\title{
Accuracy and Topography Analysis of Hard Machined Surfaces
}

\author{
János Kundrák (0000-0002-6013-7856), István Sztankovics (0000-0002-1147-7475), Viktor Molnár (0000-0002- \\ 1459-807X) \\ Institute of Manufacturing Science, University of Miskolc. H-3515 Miskolc-Egyetemvaros, Hungary, E-mail: \\ szvmv@uni-miskolc.hu
}

Research on efficient machining of hardened surfaces is invariably of interest because the number of wear resistant surfaces on the machined parts is increasing. These surfaces can be machined by both single-point (cutting) and abrasive (grinding) tools. However, in designating the finishing of the parts, the working characteristics of the products that the parts are intended for limit the finishing options. In this paper the results of a comparative experiment are introduced. In the experiments the allowances were removed from the hardened surfaces of the parts by turning, grinding or a combination of them. The comparative analyses were carried out for the roughness and accuracy of the machined surfaces and the procedures were assessed.

Keywords: Hard turning, Grinding, Surface roughness, Accuracy

\section{Introduction}

A great advancement in the development of machining procedures was made when machining of high hardness materials became possible with single-point CBN tools [1]. As a result of further development, the procedure can be applied in finishing [1,2]. In addition to the suitable cutting edge quality other conditions (machine tool, devices, etc.) had to be met. Therefore, the requirements given in the component drawing, values that could earlier be reached only by abrasive ( $\mathrm{ma}-$ inly grinding) machining, became achievable [3]. To manage this, extensive research has been underway to study hard turning. Here some topics and results of our research center can be mentioned: analysis of wear characteristics of CBN tools [4], tool-life analysis [5, 6], the connection between tool-life and cutting data $[3,7]$, and formula construction for tool-life [8].

A further aim of the research and development was that the machined parts meet completely their working requirements when built into the products, fulfilling the increasing efficiency requirements (economic, profitability). In finishing carried out by grinding this mainly means precision machining requirements. This endeavor can be tracked in the studies of the field. Some of these studies analyze the process characteristics of material removal and quality of the machined surfaces. These studies are aimed at the effects of change in the cutting data $[2,7]$ and the analysis of cutting process characteristics $[9,10]$. Integrity and quality of the machined hardened surfaces were studied by analyzing the surface roughness in grinding $[11,12]$ and in turning $[13]$ and by the alteration of the surface layer $[14,15,16]$. Numerous experiments were carried out to reach identical integrity (surface integrity, surface roughness) on hardened surfaces, e.g. on the material 100Cr6, which is easy to harden [17].

There are many disk-shaped parts which are produced in large series and are suitable for hard turning. When machining these hardened, disk-shaped parts (e.g. gears of transmission systems), accurate and economic machining has a high priority. Before the finishing operation of a gear not only the toothed area but the whole body of the gear is hardened. Therefore, all the working surfaces (e.g. bore, face, cone) have to be machined and/or the hardened layers have to be removed. In this study the machining accuracy and surface roughness of gears machined by three procedures were analyzed.

\section{Analysis and experimental conditions}

The aim of the study is the comparative analysis of surface roughness and part accuracy of bore surfaces machined by three procedures (hard turning, grinding and the combination of them).

\subsection{Process of the analysis}

The operational allowance has been removed by hard turning in the first version, by grinding in the second, and using a combination of these two in the third (Fig. 1). In the combined version of machining the turning and the grinding were done by the same machine-tool in one clamping of the workpiece. The chosen roughness parameters and the shape accuracy parameters of the bore were measured on the machined surfaces. After that the results were processed and the comparative analysis was carried out. 

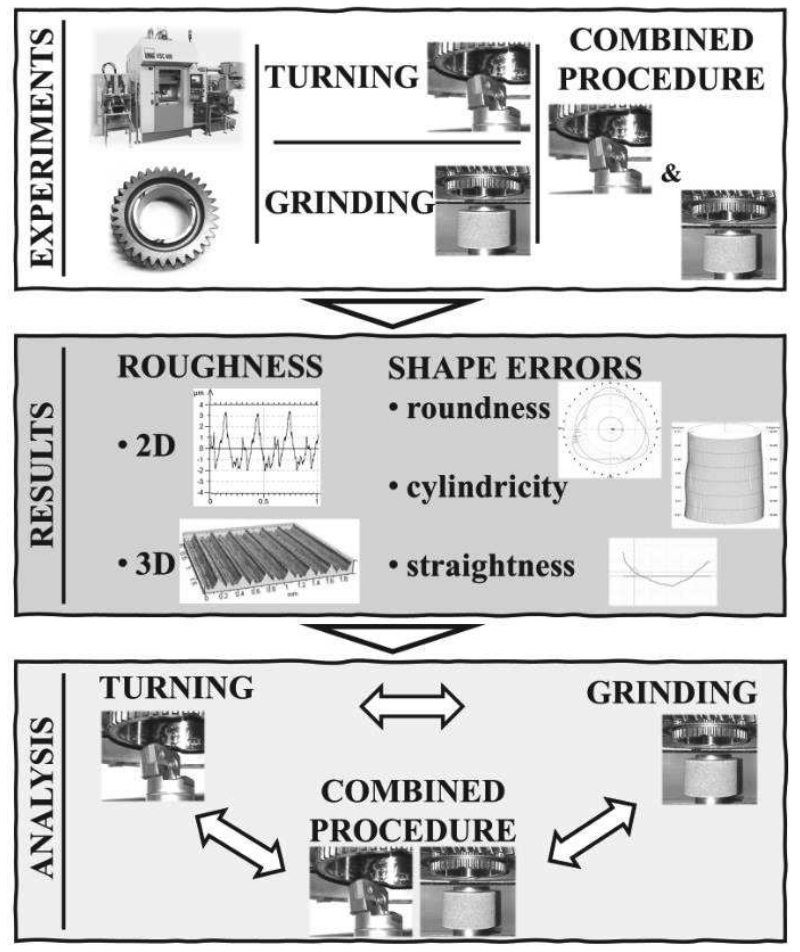

Fig. 1 The process of the analysis

\subsection{Experimental conditions}

The experiments were carried out on a hard turning lathe type EMAG VSC 400 DS. The insert type Sandvik CCGW 09T308 NC2 was chosen for the hard turning operation and it was fixed in the tool type E25T-SCLCR 09-R. The grinding operation was carried out by the bore grinding wheel type Norton 3AS80J8VET 01_36X37X13. The material of the workpiece was $20 \mathrm{MnCr} 5$, its hardness was $62-64$ HRC. The diameter of the bore of the gear was $88 \mathrm{~mm}$ and the length of it was $34 \mathrm{~mm}$. In the experiment the machining of the surface was carried out by hard turning (HT), grinding $(G)$ and the combination of them (roughing by hard turning and finishing by grinding). When hard turning was the finishing operation three different feeds were chosen and applied, which allowed expected roughness values to reach those of grinding. In all, five versions, i.e. five different surfaces $(\mathbf{A}, \mathbf{B}, \mathbf{C}, \mathbf{D}$ and $\mathbf{E})$ were analyzed. In Tab. 1 the procedure versions and the applied cutting data are summarized.

The surface topography was analyzed by line (2D) and areal (3D) surface roughness parameters. In Tab. 2 the technical parameters of the roughness measurements are summarized. The $2 \mathrm{D}$ measurement was repeated three times per workpiece bore and the location of the measured lines were designated at $120^{\circ}$ distance from each other. In the 3D measurement a $2 \times 2 \mathrm{~mm}$ area was scanned. The accuracy parameters were carried out by shape and position accuracy measuring equipment type Talyrond 365 while paying close attention to the setup parameters [18].
Tab. 1 Cutting data

\begin{tabular}{|c|c|c|c|c|c|c|}
\hline $\begin{array}{c}\text { Procedure } \\
\text { version }\end{array}$ & A & B & C & D & & E \\
\hline \multirow{2}{*}{ Procedure } & \multirow{2}{*}{\multicolumn{3}{|c|}{ HT. }} & \multirow{2}{*}{ GR. } & \multicolumn{2}{|c|}{ Combined } \\
\hline & & & & & HT. & GR. \\
\hline $\begin{array}{c}\text { Feed } \\
{[\mathrm{mm} / \mathrm{rev}]}\end{array}$ & 0.1 & 0.2 & 0.3 & 0.01 & 0.2 & 0.01 \\
\hline DoC. $[\mathrm{mm}]$ & \multicolumn{3}{|c|}{0.2} & 34 & 0.2 & 34 \\
\hline $\begin{array}{c}\text { Infeed depth } \\
{[\mathrm{mm}]}\end{array}$ & \multicolumn{3}{|c|}{ - } & 0.2 & - & 0.05 \\
\hline $\begin{array}{l}\text { W.p. rpm } \\
{[1 / \mathrm{min}]}\end{array}$ & \multicolumn{3}{|c|}{615} & 325 & 615 & 325 \\
\hline $\begin{array}{c}\text { Tool rpm } \\
{[1 / \mathrm{min}]}\end{array}$ & & 20000 & - & 20000 \\
\hline Machine tool & \multicolumn{6}{|c|}{ EM } \\
\hline
\end{tabular}

Tab. 2 Technical parameters of the surface roughness measurement

\begin{tabular}{|c|c|c|}
\hline & $2 \mathrm{D}$ & $3 \mathrm{D}$ \\
\hline Cut-off & \multicolumn{2}{|c|}{$0.8 \mathrm{~mm}$} \\
\hline Measurement length & $4 \mathrm{~mm}$ & - \\
\hline Measurement area & - & $4 \mathrm{~mm}^{2}$ \\
\hline Sensor & \multicolumn{2}{|c|}{ Inductive } \\
\hline Number of measured points & 4000 & 1 million \\
\hline Filter & \multicolumn{2}{|c|}{ Gauss } \\
\hline
\end{tabular}

\section{Experimental results}

\subsection{Results of the roughness measurement}

Roughness measurement was carried out on all the machined surfaces. The following $2 \mathrm{D}$ parameters were analyzed: average parameters - arithmetical mean height $(\mathrm{Ra})$, root mean square deviation $(\mathrm{Rq})$, skewhess (Rsk), kurtosis (Rku); peak parameter - maximum height of profile (Rz); Rk series parameters core roughness depth $(\mathrm{Rk})$. The analyzed 3D parameters were amplitude parameters - arithmetic mean height $(\mathrm{Sa})$, root mean square height $(\mathrm{Rq})$, skewness (Ssk), kurtosis (Sku), maximum height (Sz); and a functional parameter - core height (Sk) (Fig. 2).
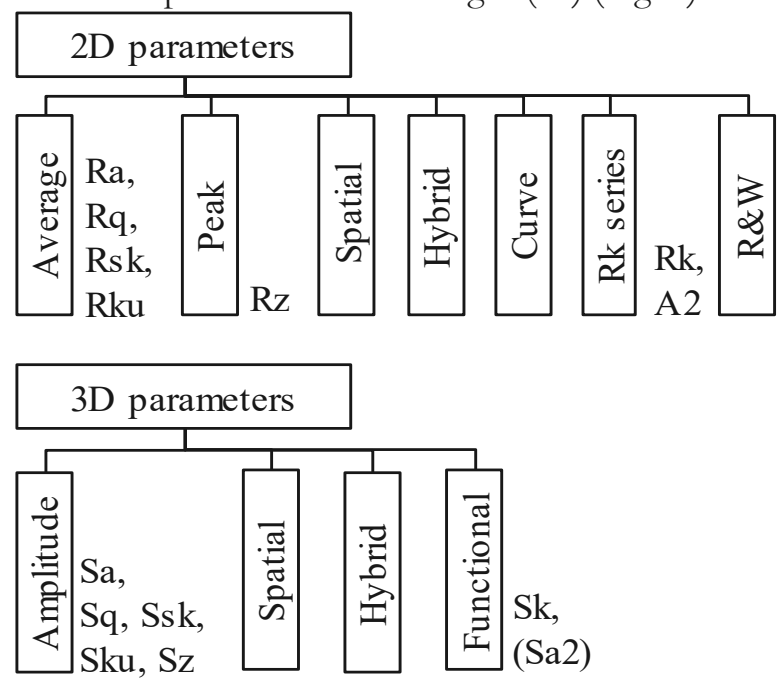

Fig. 2 The analyzed $2 D$ and $3 D$ parameters 
In Tables 3 and 4 the results of the measurements are summarized. The roughness profiles are also included in the tables.

Tab. 3 The results of the $2 D$ roughness measurement

\begin{tabular}{|c|c|c|c|c|c|}
\hline & $\mathbf{A}$ & $\mathbf{B}$ & $\mathrm{C}$ & $\mathbf{D}$ & $\mathbf{E}$ \\
\hline & 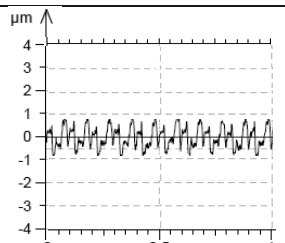 & 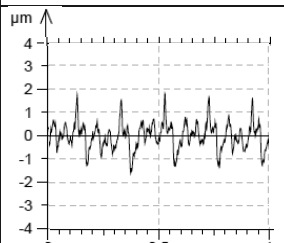 & (1) & $\begin{array}{r}\mu m \uparrow \\
4-1 \\
3 \\
2 \\
1 \\
0 \\
-1 \\
-2 \\
-3\end{array}$ & 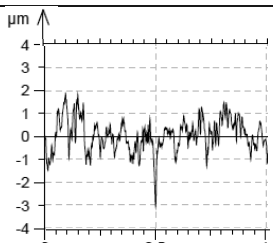 \\
\hline $\mathrm{Ra}$ [um] & $\begin{array}{cc}0 & 0.5 \\
& 03783\end{array}$ & \begin{tabular}{|cc}
0 & 0.5 \\
04346
\end{tabular} & $\begin{array}{ll}1 & 1.5 \\
& 10610\end{array}$ & $\begin{array}{ll}-4 & 0.5 \\
0 & 0.547\end{array}$ & $\begin{array}{l}0.5 \\
04853\end{array}$ \\
\hline $\operatorname{Rg}[\mu \mathrm{m}]$ & 0.4446 & 0.5683 & 1.3044 & 0.5907 & 0.6148 \\
\hline Rsk [-] & 0.1618 & 0.0063 & 0.7704 & -0.0470 & -0.0142 \\
\hline Rku [-] & 2.1077 & 3.7733 & 2.8871 & 3.5815 & 3.3436 \\
\hline $\mathrm{Rz}[\mu \mathrm{m}]$ & 1.9097 & 3.2965 & 5.4088 & 3.3932 & 3.6201 \\
\hline $\mathrm{Rk}[\mu \mathrm{m}]$ & 0.1501 & 0.1366 & 0.1215 & 0.1748 & 0.1921 \\
\hline $\mathrm{A} 2\left[\mu \mathrm{m}^{2} / \mathrm{mm}\right]$ & 5.1977 & 5.5650 & 5.1596 & 8.1290 & 9.3381 \\
\hline
\end{tabular}

Tab. 4 The results of the $3 D$ roughness measurement

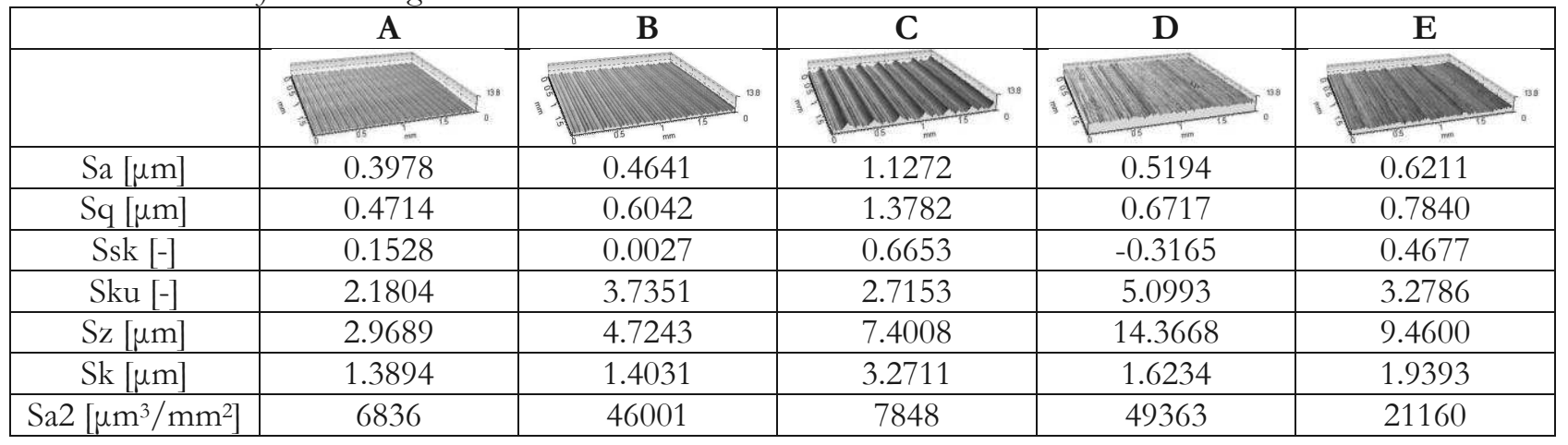

Tab. 5 Results of the shape error measurements

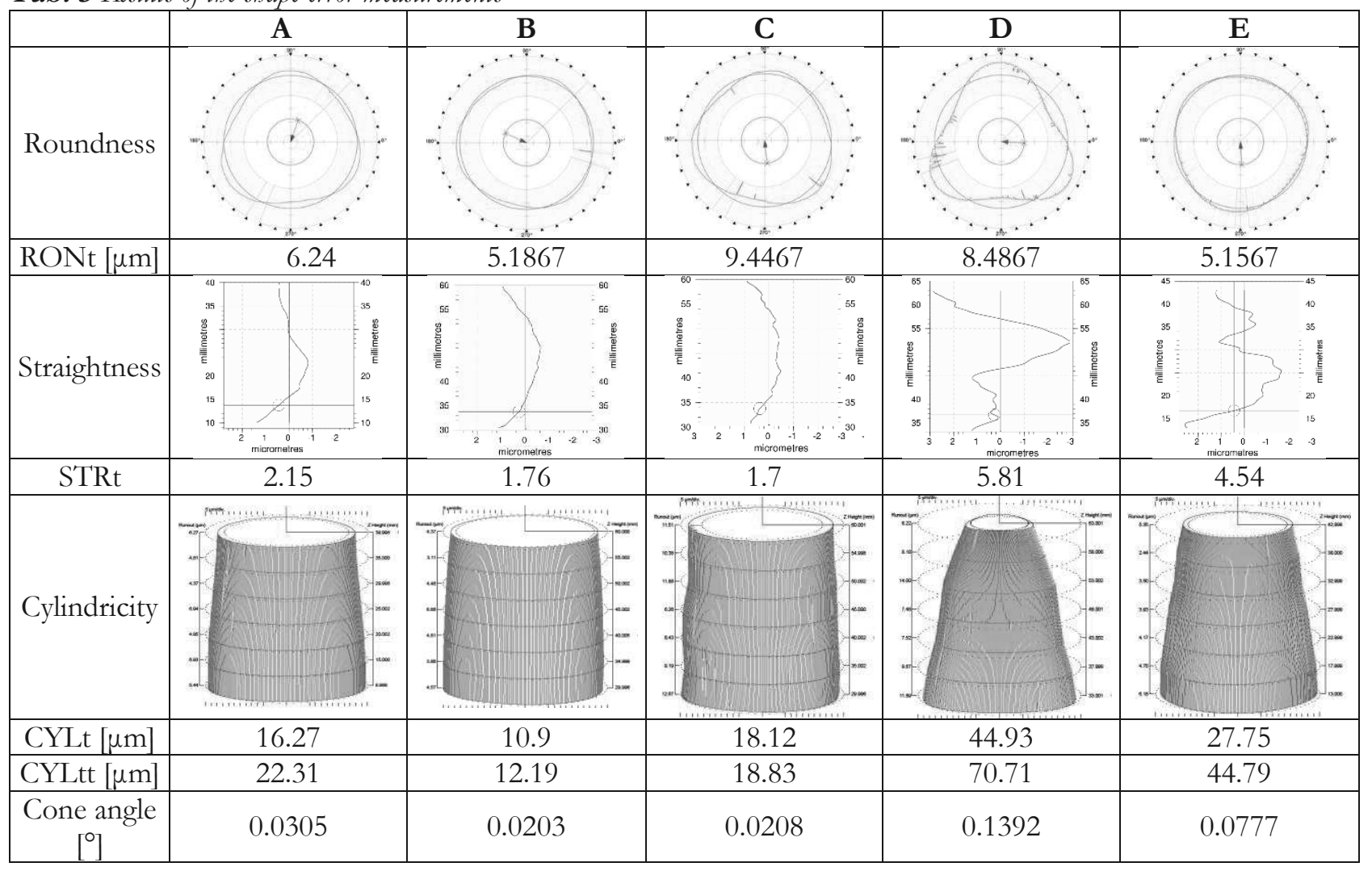




\subsection{Values of the measured shape accuracy values}

The shape accuracy of the machined bores was analyzed by the following parameters: STRt - deviation from the straight line of one directrix of the evaluated surface; RONt - roundness error in one perpendicular intersecting plane of the evaluated surface; CYLt - cylindricity error measured on the surface; CYLtt - conicity of the measured surface; Cone angle - angle of the conical error on the measured surface. In Tab. 5 the measured results and the diagrams from the surfaces obtained by the Talyrond 365 measuring device are summarized.

\section{Assessment of the results}

\subsection{Surface roughness}

The topographies of the surfaces differ in the feature of the surfaces and the values of the roughness parameters. In Figs. 3 and 4 the 2D profile and the 3D surface area of the hard turned (by the feed 0.2) and the ground surfaces are shown, respectively. The periodic nature of the turned surface and the random nature of the ground surface can be observed in these diagrams.
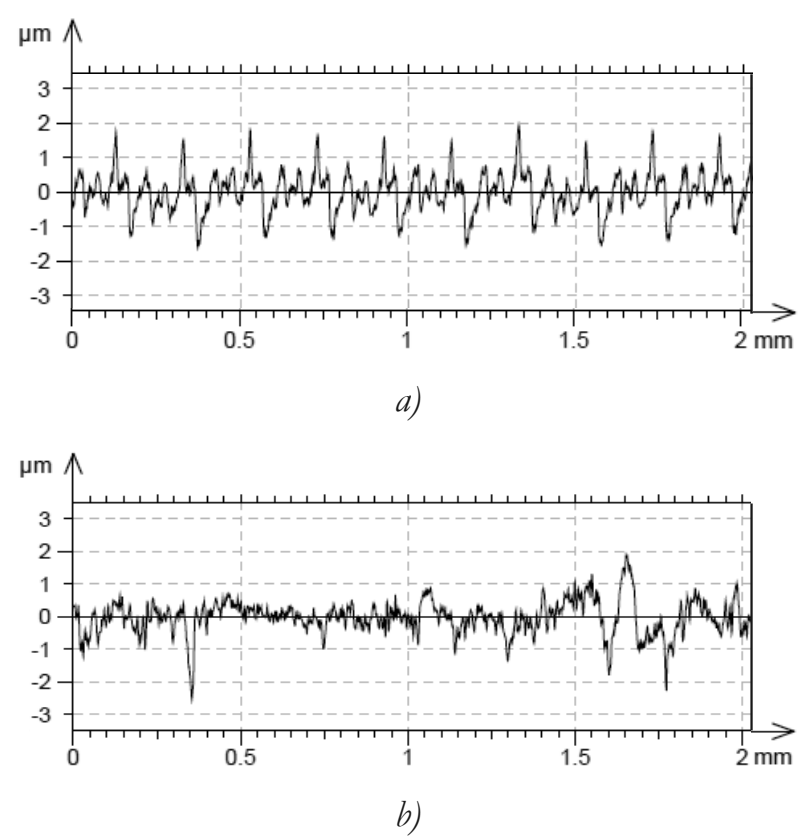

Fig. 3 Roughness profile (a: Hard turning (B), b: Grinding (D)

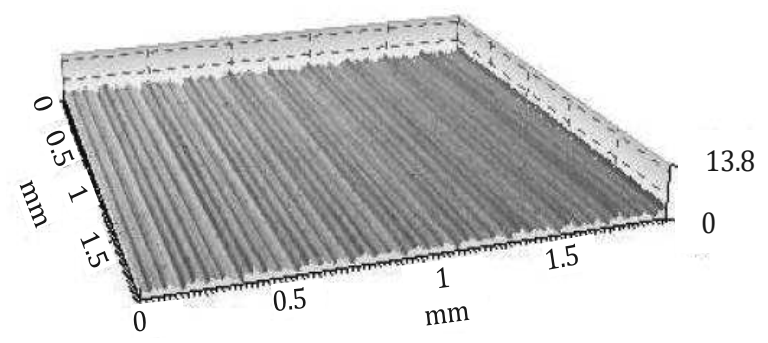

a)

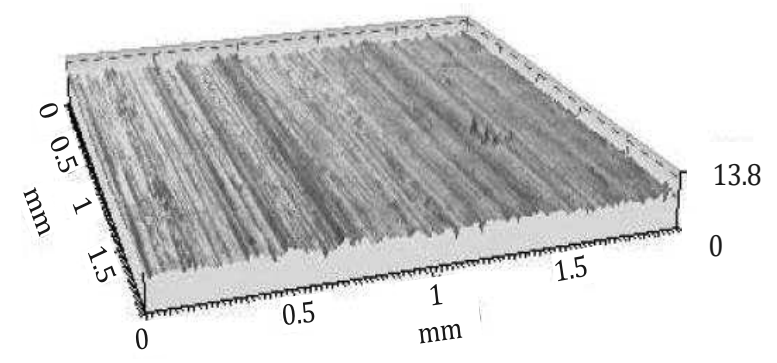

b)

Fig. 4 3D Surface topography (a: Hard turning (B), $b$ : Grinding (D)

Earlier the arithmetic mean height $(\mathrm{Ra})$ was the most frequent roughness specification in part drawings for the characterization of topography. Among the procedure versions in the experiments practically identical Ra values can be reached by low-feed turning (versions $\mathbf{A}$ and $\mathbf{B}$ ) and by grinding (versions $\mathbf{D}$ and E) (Fig. 5).

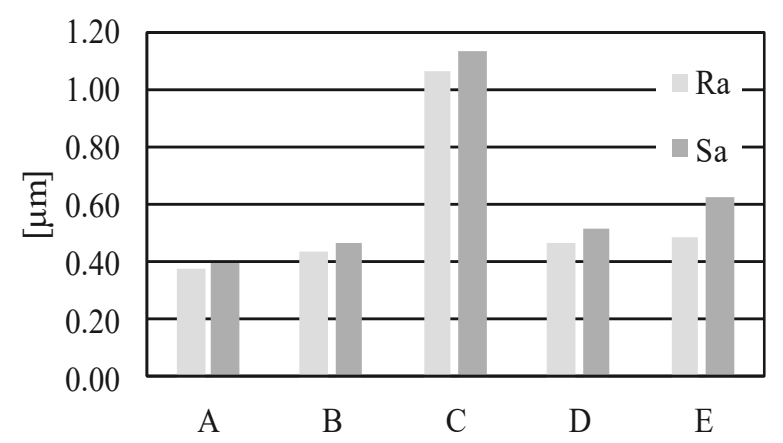

Fig. $5 \mathrm{R} a$ and $\mathrm{S} a$ values $p f$ the surfaces

In hard turning the value of $\mathrm{Ra}$ increases by the increase of the feed (Fig. 5). By increasing the feed from 0.2 to 0.3 the $\mathrm{Ra}$ value increases more than $200 \%$. The Ra values of the two ground surfaces are similar; it is only $4.4 \%$ higher in the combined procedure. The differences are similar between the analyzed procedures (Surfaces) when the Sa values are considered. The Sa values are 5-28\% higher than the Ra values. The lowest values of $\mathrm{Ra}$ and $\mathrm{Sa}$ are measured in procedure version $\mathbf{A}$ and the highest in $\mathbf{C}$.

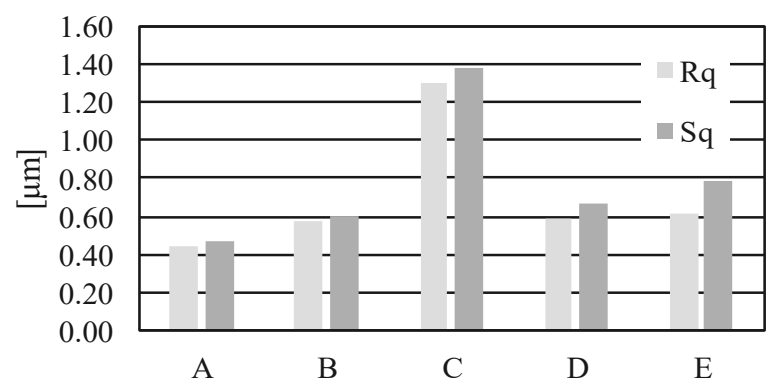

Fig. $6 \mathrm{Rq}$ and $S q$ values of the surfaces 
The rootmean square deviation $(\mathrm{Rq})$ can be used to qualify the topography of very smooth surfaces because it is more sensitive to the outlier surface peaks and valleys than the parameter Ra. The order of Rq is the same as that of the $\mathrm{Ra}$ in the machined surfaces and its value is the lowest in version $\mathbf{A}$ and the highest in version $\mathbf{C}$ (Fig. 6). The Sq value shows similar values; its value is the lowest in low-feed hard turning (versions $\mathbf{A}$ and $\mathbf{B}$ ).

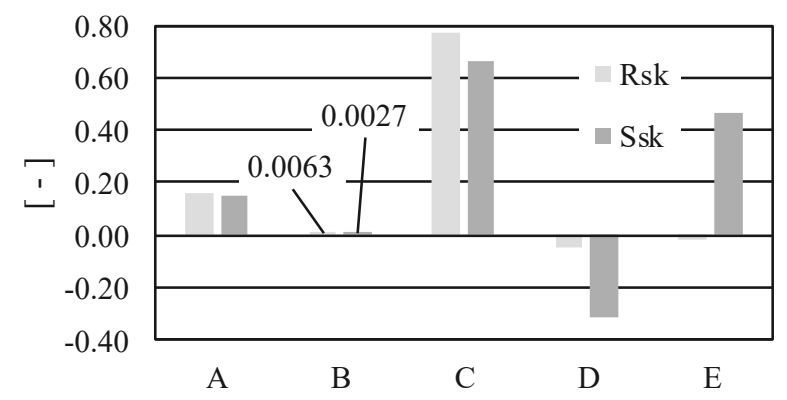

Fig. 7 Comparison of the Rsk and Ssk parameter

The working surfaces are characterized by the Rsk (skewness) and the Rku (kurtosis) parameters from the aspect of the expected tribological traits. The positive value of Rsk shows the dominance of roughness peaks and the negative value shows the dominance of valleys on the machined surface. The negative Rsk usually means better lubrication/oil-retention capability. The areal parameter of the skewness is the Ssk. The lowest values (both Rsk and Ssk) among the hard turned surfaces were obtained in procedure version $\mathbf{B}$ and among the ground surfaces in version $\mathbf{D}$. The surface turned by $0.3 \mathrm{~mm}$ feed shows the highest Rsk and Ssk values (Fig. 7). Concerning the Rku parameter, the highest value among the hard turned surfaces was obtained in procedure version $\mathbf{B}$ and among the ground surfaces in version $\mathbf{D}$ (Fig. 8). For the Sku parameter, the same results were obtained.

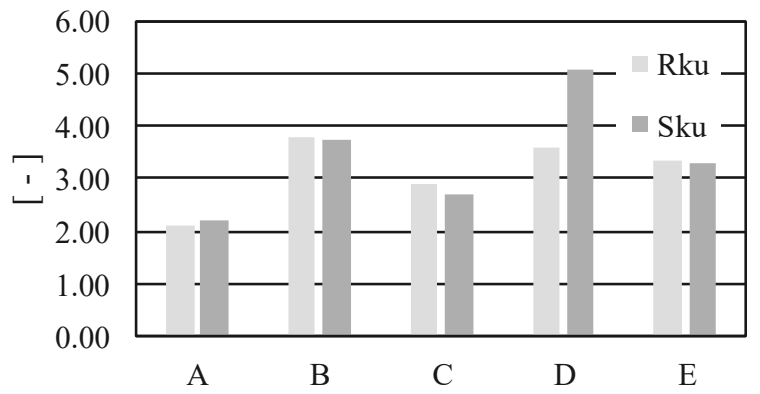

Fig. 8 The Rku and Sku values of the machined surfaces

The parallel consideration of Rsk and Rku informs us about the wear resistance of the surfaces. If a low Rsk (near 0 or negative) meets with a relatively high (3 or more) Rku value, the wear resistance of the surface increases. This can be observed in the surface which was hard turned by $0.2 \mathrm{~mm}$ feed $(\mathbf{B})$ and the ground surfaces. In case of both the skewness and kurtosis the 3D parameters can be considered more reliable. The $\mathrm{Rz}$ parameter is more sensitive to the roughness peaks and valleys than the Ra. Therefore, its application is more and more frequent. This informs us for example about the oil-retention capability between frictional surfaces. Both the Ra and Rz were - and are nowadays - considered by the constructors and manufacturers as usually sufficient parameters for qualifying the surfaces. In the $\mathrm{R} z$ values relatively great differences were obtained. The most favorable was procedure version A (hard turning by the lowest feed). The values of versions $\mathbf{B}, \mathbf{D}$ and $\mathbf{E}$ are similar (Fig. 9).

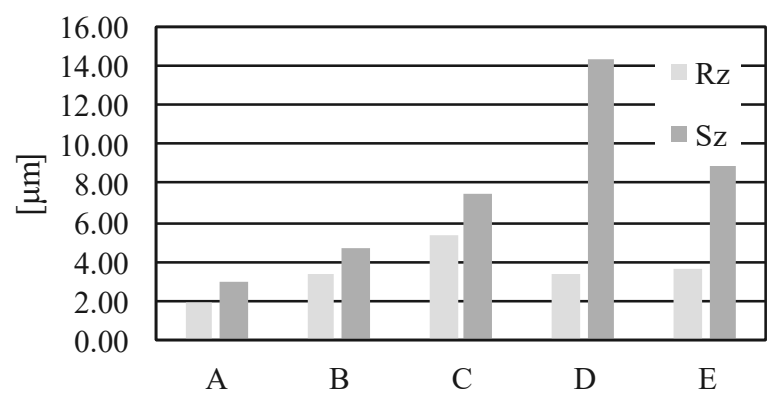

Fig. 9 Comparison of the Rz and St parameters

The values of maximum heights $(\mathrm{Sz})$ are similar to the $\mathrm{Rz}$ values but in case of the ground surfaces $(\mathbf{D}$ and $\mathbf{E}$ ) the $S z$ values differ significantly from the $\mathrm{Rz}$ values and the order of the procedure versions changes, too. The $S z$ value of the ground surface $\mathbf{D}$ can be even twice as high as those measured on the turned surfaces. The Rk and the Sk parameters are the core roughness depth and core height, respectively. A surface becomes modified with wear. The heights of roughness peaks decrease, while the bearing lengths and areas increase. From the Rk and Sk values assumptions can be made about the extent of this change. The $\mathrm{Rk}$ value slightly decreases with the increase of feed in hard turning; the Rk values of the ground surfaces are $0.2-0.7 \mu \mathrm{m}$ higher than those of the hard turned surfaces (Fig. 10).

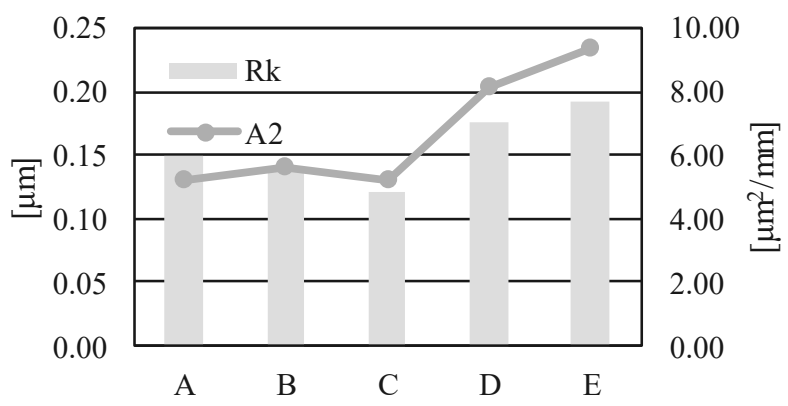

Fig. 10 Values of the Rk parameter and the $A 2$ area 
The area (A2) and the volume (Sa2) of the valley zone provide information about the oil-retention capability of a surface. The $\mathrm{A} 2$ values are relatively low when the surface is hard turned and relatively high when it is ground (Fig. 10). The latter means better oilretention capability. The highest $\mathrm{Sk}$ was measured on the surface which was hard turned at $0.3 \mathrm{~mm}$ feed. The values of the ground surfaces are slightly higher $(0.3-$ $0.5 \mu \mathrm{m})$ than those of the surfaces hard turned at low feeds (Table 4). As for the Sa2 parameter, it can be observed that its value in the surface hard turned at $0.2 \mathrm{~mm}$ feed (B) is outstandingly high. In sum it can be stated that the roughness values of ground surfaces can be reached by hard turning when $0.1 \mathrm{~mm}(\mathbf{A})$ or $0.2 \mathrm{~mm}(\mathbf{B})$ feeds are applied, if the parameters Ra, Sa, $\mathrm{Rq}, \mathrm{Sq}, \mathrm{Rz}$, and $\mathrm{Sz}$ are considered. A clear order from lower roughness to higher can be determined for the procedure versions, which is: $\mathbf{A}, \mathbf{B}, \mathbf{D}, \mathbf{E}, \mathbf{C}$. Note that $0.3 \mathrm{~mm}$ feed cannot be chosen if the roughness of the ground surface is specified. In case of a relatively high feed of the turning procedure the imprint of the tool in the base plane influences the roughness values to a high extent, while in grinding the increase of the feed leads to the increased torn feature of the surface [19].

\subsection{Evaluation of the accuracy}

In case of roundness error, we analyzed the deviation from the circle, or the sum of the highest peak and deepest valley measured from the ideal circle on the surface. The cylindricity error means the difference between the radius of the cylinders that can be written inside and outside the profile. The straightness error characterizes the curvature of the surface directrix. The diagrams from the measurement given by the measurement device (from which we show an example for procedure version B in Fig. 11) is helpful to understand the phenomenon behind the values.

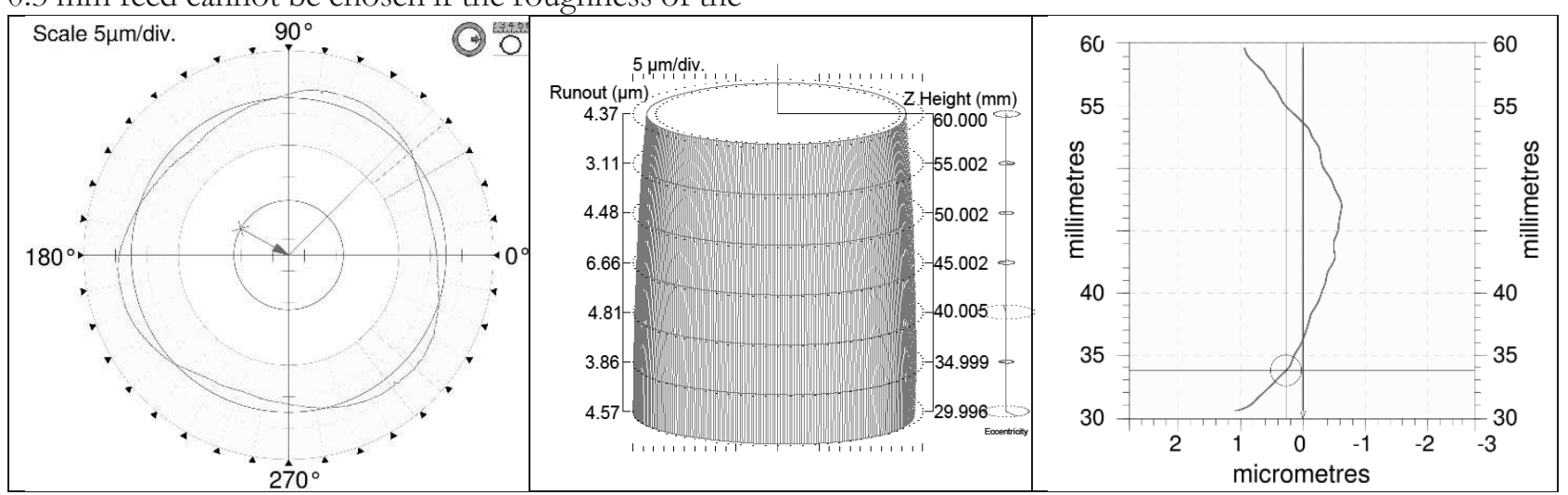

Fig. 11 Shape error characteristics after hard turning (B)

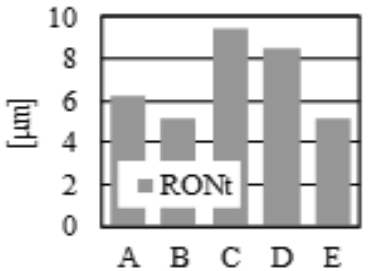

a)

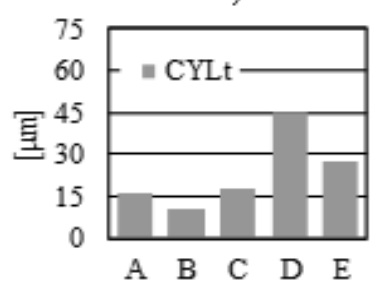

c)

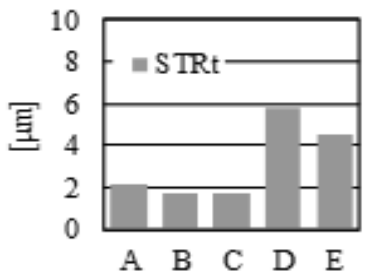

b)

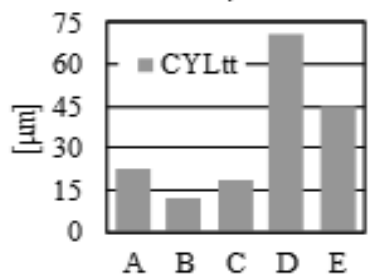

d)
Fig. 12 Alteration of the Roundness (a), Cylindricity (b), Straightness (c) and Conicity (d)

The lowest roundness error (RONt) was measured in the combined procedure. In hard turning we obtained almost the same value at $0.2 \mathrm{~mm}$ feed $(\mathbf{B})$, however RONt values were $20 \%$ higher in $0.1 \mathrm{~mm}$ feed and
$83 \%$ higher in $0.3 \mathrm{~mm}$ feed than the value of combined procedure. If we remove all of the allowance with grinding (D) we get a 64\% increase in RONt value from the result of combined process (Figure 12).

Studying the 5 procedure versions, the difference between the lowest $(5.18 \mu \mathrm{m})$ and highest $(9.44 \mu \mathrm{m})$ value of the roundness error was $4.26 \mu \mathrm{m}$. The results of the straightness error measurements were lower than the values in grinding. The measured value during the higher feed rate was lower. The straightness error increased to 3.4-fold after grinding and 2.67-fold after the combined procedure compared to the procedure version $\mathbf{C}$. The difference between the lowest and highest values is $4.11 \mu \mathrm{m}$. Analyzing the cylindricity error, we measured the most favorable value after turning with $0.2 \mathrm{~mm}$ feed. Based on this, the decrease of the feed increased CYLt by $50 \%$, the increase of the feed increased CYLt by $66 \%$. After the combined procedure, a 2.54-fold increase can be observed, while after grinding, a 4.12-fold increase is measured from $\mathbf{B}$ procedure version. In case of the cylindricity error we measured a $34.03 \mu \mathrm{m}$ higher value in the worst case than the best value, which was $10.9 \mu \mathrm{m}$. The $\mathbf{B}$ procedure version resulted in the best value of conicity. 
Based on this, in $\mathbf{A}$ the value became $83 \%$ worse while in $\mathbf{C}$ the it became $54 \%$ worse. The values of CYLtt were 5.8-fold higher in $\mathbf{D}$ and 3.67-fold higher in $\mathbf{E}$ than the result measured after 0.2 feed turning. A $58.52 \mu \mathrm{m}$ increase in conicity was recorded after grinding than after turning with 0.2 feed. To sum up, we conclude that the resultant accuracy after grinding can be achieved by hard turning with the observed conditions. We ranked the 5 procedure versions according to the studied parameters in Tab. 7.

Tab. 7 Order of the procedure versions based on the accuracy errors

\begin{tabular}{|l|c|c|c|c|c|}
\hline & A & B & C & D & E \\
\hline roundness & 3 & 1 & 5 & 4 & 1 \\
\hline cylindricity & 2 & 1 & 3 & 5 & 4 \\
\hline cone angle & 3 & 1 & 2 & 5 & 4 \\
\hline straightness & 3 & 2 & 1 & 5 & 4 \\
\hline
\end{tabular}

\section{Discussion}

Three precision machining procedures and five bore surfaces were analyzed. The cutting data of the hard turning procedure were chosen to reach the roughness and accuracy specifications given in the part drawing, fulfilled by the grinding procedure. The cutting data of hard turning differed in the value of the feed. The specified values were expected to be reached with the chosen cutting data. Five procedure versions were analyzed. They are options from which the best can be chosen based on features such as the working characteristics of the part, economic efficiency, surface topography, etc. This decision has to be made carefully.

When planning the machining technology, if the working characteristics of the surface are taken into account, it has to be considered whether a periodic or random surface is more favorable. In the latter case, despite the suitable roughness values, a hard turned surface cannot be recommended. Ground topography is needed if, for example, the surfaces have relative movements, or they are sealing surfaces. Of the two analyzed procedures $(\mathbf{D}, \mathbf{E})$ the combined one is the more economical way to obtain a ground topography because a great extent of the allowance is removed by turning. The combined procedure, which is carried out on one machine-tool in one clamping, results in roughness and accuracy values that are nearly identical to values for grinding, but the allowance removal requires significantly less coolant and lubricant, therefore the environmental load will be lower [20].

When in the manufacturing chain the whole gear is case hardened instead of hardening only the toothed part of the gear, hard turning could be more advantageous because if necessary, more than one working surface can be machined in one clamping.

\section{Summary}

In this paper a comparative analysis of machining procedure versions of disk-shaped parts (material: 20MnCr5, hardness: 62-64 HRC, surface: bores of gears) were carried out. In the study the accuracy and surface roughness of hardened surfaces were analyzed. The machining allowances were removed by turning, grinding and the combination of them. It was found that, except for the turning carried out at the highest feed, in the four procedure versions nearly identical roughness values can be reached. This means that it is possible to choose a periodic or random surface topography according to the working requirements based on the same roughness specifications. Moreover, the optional versions can be assessed based on economic efficiency aspects. Considering accuracy analyses, too, versions $\mathbf{B}$ and $\mathbf{E}$ can be recommended for periodic or random topography, respectively.

\section{References}

[1] TONSHOFF, H. K.., ARENDT, C.; BEN AMOR, R. (2000). Cutting of hardened steel. In: Annals of the CIRP, Vol. 49, No. 2, pp.547566.

[2] BARTARYA, G., CHOUDHURY, S. K. (2012). State of the art in hard turning. In: International Journal of Macbine Tools and Manufacture, Vol. 53, No. 1, pp.1-14.

[3] KLOCKE, F., BRINKSMEIER, E., WEINERT, K. (2005). Capability Profile of Hard Cutting and Grinding Process. In: Annals of the CIRP, Vol. 54, No. 1, pp.22-45.

[4] HUANG, Y, CHOU, Y. K., LIANG, S. Y. (2007). CBN tool wear in hard turning: a survey on research progresses. In: The International Journal of Advanced Manufacturing Technology, Vol. 35., pp.443-453.

[5] KUNDRAK, J., PALMAI, Z. (2019). The Change of Tool Life in a Wide Range of Cutting Speeds in Hard Turning. In: Manufacturing Technology, Vol. 19, No. 2, pp.254-260.

[6] MAJERIK, J., BARENYI, I. (2018). Wear and Tool Life Investigation of Carbide Inserts while Hard Machining of Armox 500 Steel. In: Manufacturing Technology, Vol. 18, No. 2, pp.273-278.

[7] BARTARYA, G., CHOUDHURY, S. K. (2012). Effect of cutting parameters on cutting force and surface roughness during finish hard turning AISI52100 grade steel. In: Procedia CIRP, No. 1, pp.651-656.

[8] MAMALIS, A. G., KUNDRAK, J., HORVATH, M. (2005). On a novel tool life relation for precision cutting tools. In: Journal of 
Manufacturing Science and Enginering, Vol.127, No. 2, pp.328-332.

[9] POULACHON, G., MOISAN, A. L. (2000). Hard turning: chip formation mechanisms and metallurgical aspects. In: Journal of Manufacturing Science and Engineering, Vol. 122, No. 3, pp.406-412.

[10] CHEN, L., TAI, B. L., CHAUDHARI, R. G., SONG, X., SHIH, A. J. (2017). Machined surface temperature in hard turning. In: International Journal of Macbine Tools \& Manufacture, No. 121, pp.10-21.

[11] NOVAK, M. (2011). Surface quality of hardened steels after grinding. In: Manufacturing Technology, Vol. 11, No. 1, pp.55-59.

[12] FARSKY, J., BAKSA, T., ZETEK, M. (2020). Grinding of Maraging Steel 1.2709 with SiC Grinding Wheels and Effect of Grinding Conditions on the Surface Roughness and Wear of the Wheels. In: Manufacturing Technology, Vol. 20, No. 1, pp.18-22.

[13] OZEL, T., KARPAT, Y. (2005). Predictive modeling of surface roughness and tool wear in hard turning using regression and neural networks. In: International Journal of Machine Tools Manufactuing, No. 45, pp.467-479.

[14] KUNDRAK, J., GACSI, Z., GYANI, K., BANA, V., TOMOLYA, K. (2012). X-ray diffraction investigation of white layer development in hard-turned surfaces. In: International Journal of Advanced Manufacturing Technology, Vol. 62, No. 5-8, pp. 457-469.
[15] ALOK, A., DAS, M. (2019). White layer analysis of hard turned AISI 52100 steel with the fresh tip of newly developed HSN2 coated insert. In: Journal of Manufacturing Processes, Vol. 46, pp.16-25.

[16] KUNDRAK, J., MAMALIS, A. G., GYANI, K., BANA, V. (2011). Surface layer microhardness changes with high-speed turning of hardened steels. In: International Journal of Advanced Manufacturing Technology, Vol. 53, No. 1-4, pp.105-112.

[17] SEDLAK, J., TROPP, P., CHLADIL, J., OSICKA, K., SLIWKOVA, P. (2015). HighSpeed Cutting of Bearing Rings from Material 100Cr6. In: Manufacturing Technology, Vol. 15, No. 5, pp.899-908.

[18] VIT, J., NOVAK, M. (2018). A Roundness Machine Measuring Probe Calibration. In: Manufacturing Technology, Vol. 18, No. 6, pp.10531059.

[19] DOBROCKY, D., STUDENY, Z., POKORNY, Z., JOSKA, Z., FALTEJSEK, P. (2019). Assessment of Surface Structure of Machined Surfaces. In: Manufacturing Technology, Vol. 19, No. 4, pp.563-572.

[20] GAJRANI, K., SURESH, S., SANKAR, M. R. (2018). Environmental friendly hard machining performance of uncoated and MoS2 coated mechanical micro-textured tungsten carbide cutting tools. In: Tribology International, Vol. 125, pp.141-155. 